\title{
Risk Factors for Fecal and Urinary Incontinence After Childbirth: The Childbirth and Pelvic Symptoms Study
}

Kathryn L. Burgio, Ph.D., ${ }^{1,2}$ Diane Borello-France, P.T., Ph.D., ${ }^{3}$ Holly E. Richter, Ph.D., M.D., ${ }^{1}$ Mary Pat FitzGerald, M.D., ${ }^{4}$ William Whitehead, Ph.D., ${ }^{5}$ Victoria L. Handa, M.D., ${ }^{6}$ Ingrid Nygaard, M.D., Paul Fine, M.D., ${ }^{8}$ Halina Zyczynski, M.D., ${ }^{9}$ Anthony G. Visco, M.D., ${ }^{5}$ Morton B. Brown, Ph.D., ${ }^{10}$ Anne M. Weber, M.D., M.S., ${ }^{11}$ for The Pelvic Floor Disorders Network

${ }^{1}$ University of Alabama at Birmingham, Birmingham, Alabama; ${ }^{2}$ Birmingham VA Medical Center; Birmingham, Alabama; ${ }^{3}$ Duquesne University, Pittsburgh, Pennsylvania; ${ }^{4}$ Loyola University, Chicago, Illinois; $;{ }^{5}$ University of North Carolina, Chapel Hill, North Carolina; ${ }^{6}$ Johns Hopkins University, Baltimore, Maryland; ${ }^{7}$ University of Utah, Salt Lake City, Utah; ${ }^{8}$ Baylor College of Medicine, Houston, Texas; ${ }^{9}$ University of Pittsburgh, Pittsburgh, Pennsylvania; ${ }^{10}$ University of Michigan, Ann Arbor, Michigan; and ${ }^{11}$ National Institute of Child Health and Human Development, NIH

OBJECTIVE: To identify risk factors for postpartum $\mathrm{FI}$ and UI.

METHODS: $\quad$ Secondary analysis of data from the CAPS study, which estimated the prevalence of postpartum FI and $\mathrm{UI}$ in primiparous women with clinically recognized anal sphincter tears after vaginal delivery, compared with women who delivered vaginally without recognized tears or by cesarean before labor. A total of 921 women were enrolled while in the hospital and $759(82 \%)$ were interviewed by telephone 6 months postpartum. FI was assessed using the FISI and UI using the Medical, Epidemiological, and Social Aspects of Aging Questionnaire. Fl risk factor analyses were conducted within each group, because of higher prevalence in the tear group. UI analyses were conducted with the groups combined.

RESULTS: $\quad$ In women with sphincter tears, $\mathrm{Fl}$ at 6 months was associated with white race $(0 \mathrm{R} 6.1,95 \% \mathrm{Cl}$ 1.3-29.4), antenatal UI (OR 2.2, Cl 1.1-4.3), 4th versus 3rd degree tear (OR 2.0, Cl 1.0-4.0), older age at delivery (OR 1.6 per $5 \mathrm{yr}, \mathrm{Cl}$ 1.2-2.1), and higher body mass index (BMI) (OR 1.3 per 5 $\left.\mathrm{kg} / \mathrm{m}^{2}, \mathrm{Cl} 1.0-1.7\right)$. No factors were associated with $\mathrm{Fl}$ in the vaginal or cesarean control groups. Across all groups, risk factors for postpartum UI were antenatal UI (OR 3.5, Cl 2.4-5.2), less education (OR 2.0, $\mathrm{Cl}$ 1.4-2.8), and higher BMI (OR 1.2 per $5 \mathrm{~kg} / \mathrm{m}^{2}, \mathrm{Cl} 1.1-1.4$ ); cesarean delivery was protective (OR $0.5, \mathrm{Cl} 0.3-0.9$ ).

CONCLUSIONS: Postpartum FI and UI are associated with few modifiable risk factors. However, the presence of antenatal UI and high BMI may help clinicians target at-risk women for early intervention.

(Am J Gastroenterol 2007;102:1998-2004)

\section{INTRODUCTION}

Anal sphincter tear at the time of vaginal delivery is a major cause of fecal incontinence (FI) in young women (1-3). Prior studies by our group (4) and others have demonstrated that the occurrence of a sphincter tear approximately doubles the risk of FI 6 months after delivery. While sphincter tear is a strong risk factor for FI, only a minority of women who sustain sphincter tears report FI, possibly because of successful repair or other protective factors. Conversely, those who deliver vaginally without a tear, and even those who deliver by cesarean section prior to labor, are not completely protected from the development of new FI symptoms (4-6). Incident FI in such cases is presumably because of either occult lacerations or anatomic and/or physiologic changes that occur during pregnancy and delivery. Thus, sphincter tear is not inevitably coupled with FI and it is important to understand other variables that may increase the risk of FI associated with vaginal delivery.

We previously reported that in a cohort of primiparous women participating in the Childbirth and Pelvic Symptoms (CAPS) study, FI symptoms were significantly more common after vaginal delivery with anal sphincter tear than after vaginal delivery without sphincter tear or after cesarean delivery prior to labor $(17 \%, 8 \%$, and $8 \%$, respectively) (4). However, urinary incontinence (UI) symptoms were not significantly different across the three groups, affecting $22-34 \%$ of women 6 months postpartum. The objective of this secondary analysis of data from the CAPS study was to determine which women were at highest risk for FI and UI 6 months 
postpartum, and whether any maternal or obstetrical characteristics modify the effect of sphincter tear. Through this research we hoped to identify characteristics of women for whom interventions to prevent or ameliorate symptoms might be indicated.

\section{MATERIALS AND METHODS}

The CAPS study was performed by the Pelvic Floor Disorders Network (PFDN), a cooperative agreement network funded by the National Institute of Child Health and Human Development (NICHD). Subjects were enrolled from the seven PFDN clinical sites listed in the Appendix. Each clinical site and the data coordinating center received Institutional Review Board approval for the protocol and all participants provided written informed consent. Details of the study methodology are described elsewhere (4).

\section{Participants and Recruitment}

Primiparous women hospitalized between September 2002 and September 2004 were approached after delivery for enrollment into one of the three cohorts. The first cohort included women with clinically recognized anal sphincter tear (i.e., 3rd or 4th degree perineal tear) and repaired at the time of delivery (sphincter tear group). This group included women with or without episiotomy. The second cohort was a control group that included women who delivered vaginally without a clinically recognized anal sphincter tear (vaginal control group); these women may have had a 1 st or 2 nd degree perineal tear or nonextending episiotomy. The final cohort was a second control group that included women who underwent a cesarean delivery without labor (cesarean control group).

Inclusion criteria included singleton delivery, $\geq 37$ wk gestation, and ability to participate in telephone interviews. Exclusion criteria were inflammatory bowel disease, selfreported prepregnancy FI or ano-rectal surgery, and neurological conditions predisposing to UI or FI.

\section{Procedures and Measurement}

Participants were interviewed while still in the hospital to document demographic information and history of UI before or during pregnancy using the following questions: "During your pregnancy, how often did you experience any amount of accidental urine loss?" and "Before you became pregnant, how often did you experience any amount of accidental urine loss?" Response options for both questions were "never," "rarely," "sometimes," or "often." Patients who responded "sometimes" or "often" were defined as having experienced UI during these periods. At $6 \mathrm{wk}$ and 6 months postpartum, participants were interviewed by telephone to assess symptoms of FI and UI using validated questionnaires.

FI was assessed with the Fecal Incontinence Severity Index (FISI) (7), which assesses the frequency of four symptoms (incontinence of gas, mucus, liquid stool, and solid stool). Presence of FI was defined as any involuntary leakage of mu- cus, liquid stool, or solid stool on the FISI. Subjects with only flatal incontinence were not considered to have FI. The FISI total score summarizes the type and frequency of fecal loss, and is computed from all four components, including gas. Therefore, in this paper the definition of FI does not include gas; but the FISI score does include gas in its computation.

UI symptoms were assessed using the Medical, Epidemiological, and Social Aspects of Aging (MESA) questionnaire (8). Presence of UI was defined by a response of "sometimes" or "often" to any of the MESA questions. The MESA score is the average of the responses to all the MESA items, rescaled to range from $0-100$.

\section{Data Analysis}

Our primary objective was to identify risk factors associated with FI and UI at 6 months postpartum for each cohort (sphincter tear, vaginal control, and cesarean control) separately. In doing so, we conducted separate analyses representing the dependent variables (FI and UI) as dichotomous (presence of FI/UI defined previously in the methods) and continuous (FISI and MESA total scores) outcomes.

A priori, we identified the following independent variables for exploration in each cohort analysis: demographic variables (age, race, education, marital status), predelivery body mass index (BMI), fetal characteristics (head circumference, birth weight), and history of UI before or during pregnancy. For the sphincter tear and vaginal control group analyses, we also examined the following obstetrical variables: duration of second stage labor, labor augmentation, type of analgesia, use of forceps or vacuum, shoulder dystocia, episiotomy, and perineal laceration. Additionally, the sphincter tear group analyses considered degree of perineal laceration ( $3 \mathrm{rd} v \mathrm{~s} 4 \mathrm{th})$; however, technical details of the sphincter repair were not explored as they were inconsistently reported in the medical record. Independent variables specific to the cesarean delivery group analyses included type of analgesia and the indication for cesarean delivery.

We first performed all-possible subsets regression for each dependent variable and cohort (as described above), including all potential risk variables (excluding a few with large numbers of missing values). All-possible subsets regression identifies sets of variables that best explain the dependent variable with one, two, three, etc., independent variables in the model. This enables the analyst to identify all the variables that might contribute to a final model or, conversely, to eliminate variables that clearly would not be part of the final model. This process is appropriate both when the dependent variable is continuous or discrete, since the purpose is not to estimate the coefficients, but only to identify potential multivariate associations.

Next, we conducted stepwise forward and backward logistic regression with the dependent variable defined as the presence/absence of FI or UI. To determine if severity of symptoms confirmed or changed the observed associations, we repeated the stepwise forward and backward regression using the FISI or MESA total score as the dependent variable. 
The regression analyses included the best subset of independent variables representative of the three cohorts that obtained a level of statistical significance $<0.05$.

Based on the results of the all-possible subsets regression, the following independent variables were included in the stepwise regression analyses for all three cohorts: age, race, history of UI during pregnancy, predelivery BMI, and infant head circumference. Other variables specific to within-cohort analyses were duration of second stage of labor (sphincter tear and vaginal control), tear grade (sphincter tear), and reasons for cesarean delivery, including breech or malpresentation and other abnormality (cesarean control). Because values for infant head circumference and duration of second stage labor were missing for many cases, these two variables were added into the regression analysis after the final model was determined. The same set of variables was used for the analyses of FI as a dichotomous variable (presence or absence by FISI) and as a continuous variable (FISI score).

Our secondary aim was to determine risk factors for FI and UI regardless of delivery route or presence of sphincter laceration. We performed similar analyses as described previously but with data collapsed across the cohorts. For these analyses, we explored only the independent variables common across the three cohorts, a variable to differentiate between the vaginal tear and vaginal control cohorts, and a variable to differentiate between the cesarean control and vaginal control cohorts.

\section{Sample Size}

The two larger cohorts (sphincter tear and vaginal control) each had approximately 320 observations and the cesarean control had approximately 100 observations. Therefore, in the larger cohorts there is $80 \%$ power to identify independent variables that have a correlation of 0.16 with the dependent outcome measure using a 2 -tailed test at a $5 \%$ level of significance and $90 \%$ power to identify a correlation of 0.18 . In the smallest cohort there is $80 \%(90 \%)$ power to identify independent variables that have a correlation of $0.28(0.32)$.

\section{RESULTS}

\section{Characteristics of Participants}

Of the 921 women who participated in the CAPS study, 759 (82\%) completed interviews at 6 months: 335 in the sphincter tear group, 319 in the vaginal control group, and 105 in the cesarean control group. The analysis is based on data from the 759 women who completed the 6-month interview. Descriptive characteristics of the women are presented by cohort in Table 1.

\section{Postpartum FI}

Within the sphincter tear cohort, the presence of FI at 6 months was associated with white race, antenatal UI, 4th versus 3 rd degree sphincter tear, older age at time of delivery, and higher BMI (Table 2). When duration of second stage of labor was added to the model, it was significantly associated with FI and tear grade became nonsignificant. When the FISI score was used as the outcome, the associations did not differ from those found for FI.

In the vaginal control group, the only independent variable that approached statistical significance for the presence of FI was a history of UI during pregnancy. Using the FISI score as the outcome supported this finding $(P<0.001)$. There were very few cases of FI in the cesarean control cohort and no variables were found to be associated with the presence of FI.

With data from the three cohorts combined, the presence of FI was found to be associated with experiencing a $3 \mathrm{rd}$ or 4 th degree sphincter tear, being older at the time of delivery, having a higher predelivery BMI, and antenatal UI (Table 2). The regression analysis performed using the FISI score as the outcome, confirmed results found with the presence of FI across all cohorts, as well as of the individual cohort analyses.

\section{Postpartum UI}

Because there were no significant cohort effects for UI prevalence at 6 months postpartum in the parent study, there was no

Table 1. Characteristics of the Participants $(\mathrm{N}=759)$

\begin{tabular}{|c|c|c|c|}
\hline Variable & $\begin{array}{l}\text { Sphincter Tear } \\
(\mathrm{N}=335)\end{array}$ & $\begin{array}{l}\text { Vaginal Control } \\
\quad(\mathrm{N}=319)\end{array}$ & $\begin{array}{c}\text { Cesarean Control } \\
(\mathrm{N}=105)\end{array}$ \\
\hline Age, years (mean $(\mathrm{SD}))$ & $27.8(5.9)$ & $26.4(5.7)$ & $30.2(6.8)$ \\
\hline Married/living with partner (\%) & 71.3 & 60.5 & 72.4 \\
\hline \multicolumn{4}{|l|}{ Race $(\%)$} \\
\hline White & 72.2 & 67.7 & 76.2 \\
\hline Black & 16.4 & 23.5 & 15.2 \\
\hline Asian & 5.4 & 2.8 & 2.9 \\
\hline Other & 6.0 & 5.9 & 4.8 \\
\hline Hispanic ethnicity $(\%)$ & 7.2 & 6.3 & 4.8 \\
\hline Education: some college or above $(\%)$ & 76.7 & 67.4 & 80.0 \\
\hline Prepregnancy BMI, $\mathrm{kg} / \mathrm{m}^{2}$ (mean [SD]) & $24.5(5.3)$ & $25.2(5.4)$ & $27.4(7.4)$ \\
\hline *UI during pregnancy $(\%)$ & 19.4 & 20.7 & 21.9 \\
\hline
\end{tabular}

*Urinary incontinence defined as a response of "sometimes" or "often" to any one or more of the 15 questions on the Medical, Epidemiological, and Social Aspects of Aging (MESA) questionnaire. 
Table 2. Risk Factors for Fecal and Urinary Incontinence

\begin{tabular}{|c|c|c|c|}
\hline & Odds Ratio & 95\% Confidence Interval & $P$ Value \\
\hline \multicolumn{4}{|l|}{ FI in sphincter tear group } \\
\hline White race & 6.1 & $1.3-29.4$ & 0.025 \\
\hline Antenatal UI & 2.2 & $1.1-4.3$ & 0.026 \\
\hline 4th versus 3 rd degree tear & 2.0 & $1.0-4.0$ & 0.041 \\
\hline Older age at time of delivery (per 5 yr) & 1.6 & $1.2-2.1$ & 0.0031 \\
\hline Higher predelivery BMI (per $5 \mathrm{~kg} / \mathrm{m}^{2}$ ) & 1.3 & $1.0-1.7$ & 0.043 \\
\hline \multicolumn{4}{|l|}{ FI across cohorts } \\
\hline 3 rd or 4 th degree tear & 2.6 & $1.6-4.2$ & $<0.0001$ \\
\hline Older age at time of delivery (per 5 yr) & 1.4 & $1.1-1.7$ & 0.0009 \\
\hline Higher predelivery BMI (per 5 kg/m²) & 1.2 & $1.0-1.4$ & 0.032 \\
\hline Antenatal UI & 2.4 & $1.5-3.9$ & 0.0005 \\
\hline \multicolumn{4}{|l|}{ UI across cohorts } \\
\hline Antenatal UI & 3.5 & $2.4-5.2$ & $<0.0001$ \\
\hline No college education & 2.0 & $1.4-2.8$ & 0.0002 \\
\hline Higher predelivery BMI (per $5 \mathrm{~kg} / \mathrm{m}^{2}$ ) & 1.2 & $1.1-1.4$ & 0.0008 \\
\hline Cesarean delivery & 0.5 & $0.3-0.9$ & 0.017 \\
\hline
\end{tabular}

justification for examining the risk factors for UI within the cohorts separately, as was done for FI. Therefore, the analyses presented below were conducted with the combined sample, controlling for cohort.

Based on the results of the all-possible subsets regression, the following independent variables were included in the stepwise regression analyses: education, history of UI during pregnancy, predelivery BMI, and cohort. We used the same set of variables in the analyses regardless of whether UI was analyzed as a dichotomous (presence or absence by MESA) or as a continuous (MESA score) variable.

Across all groups, the presence of postpartum UI was associated with antenatal UI, no college education, and higher predelivery BMI, while cesarean delivery before labor was protective (Table 2). The regression analysis performed using the MESA score yielded the same associations.

\section{DISCUSSION}

While many studies have evaluated risk factors for anal sphincter tear, few have addressed risk factors for FI and UI amongst women once they have sustained a tear. By studying this, we hoped to identify factors that would be useful in clinical care and drive future prospective research. The analyses and risk factors for postpartum FI and UI differed and are discussed separately below.

\section{Fecal Incontinence}

In the group of women who sustained a sphincter tear, FI was associated with white race, antenatal UI, 4th versus 3 rd degree tear, older age at time of delivery, and higher predelivery BMI. We found no factors associated with FI in either the vaginal control or the cesarean control group. This was not surprising, as the prevalence of FI in these groups was very low.
Earlier obstetric surveys suggested that the risk of sphincter tear during delivery is greater in whites than in blacks and lower in whites than in Asians (9). These reports were corroborated and extended in the present study. After recruiting vaginal controls in a manner that insured they would be representative of all women in these clinics who delivered without sustaining a 3rd or 4th degree sphincter tear, women in the vaginal control group were more likely to be black $(24.4 \%)$ than women in the sphincter tear group (15.4\%) (see Table 1). While this association between race and the risk of sphincter tear has been reported previously (10), the new finding is our observation that white women with sphincter tears were more likely to develop FI than were black women with sphincter tears. Further studies are needed to identify the physiological or anatomical basis for this difference.

While age has previously been identified as a significant risk factor for FI in population-based studies (9), the assumption has been that age-associated changes in risk are limited to women over the age of $40(9,11,12)$. This is the first study to show that age is associated with increased risk of FI in women who are young enough to be bearing their first child. Previous research has reported that older age at delivery is associated with a higher rate of obstetrical complications (13), indicating that the association between age at delivery and FI may be mediated by one or more of these other complications.

BMI has been identified as a significant risk factor for FI in population-based and clinic-based studies $(11,14)$. However, in this study of postpartum women, BMI was correlated with FI in the sphincter tear group only, and not in the vaginal control or cesarean control groups. This suggests an interaction between BMI and a pelvic floor weakened by sphincter tear. Because obesity is associated with increases in intraabdominal pressure (15), it is possible that the mechanical load of increased body weight pressing on the pelvic floor may contribute to breakdown of the sphincter repair performed 
at the time of delivery in these women. Prospective studies are needed to determine whether BMI is associated with progressively deteriorating anal canal squeeze pressures or morphological evidence of sphincter disruption following sphincter repair.

\section{Urinary Incontinence}

The risk factors identified for postpartum UI were antenatal UI, not having a college education, and higher predelivery BMI. Similar to most other studies of postpartum UI in primiparous women $(16,17)$, we also found a significantly lower prevalence of UI in women undergoing cesarean delivery. The association between BMI and postpartum UI is also consistent with previous research (18). Previous studies have reported an increase in UI prevalence during pregnancy and following delivery (19). But, it is unclear whether the mechanisms responsible for the increased frequency of UI during pregnancy are the same as those responsible for postpartum UI. However, it is well established that the presence of UI during pregnancy identifies women who are at greater risk for postpartum UI $(20,21)$.

We were interested to see that antenatal UI was also an independent risk factor for postpartum FI in women who sustained an anal sphincter laceration. Previous reports have identified UI as a risk factor for FI $(9,11)$, but our report is unique in that it shows that UI during pregnancy is a risk factor for postpartum FI. Antenatal UI may prove to be an important clinical marker of pelvic floor function. It is possible that selfreported antenatal UI identifies women with weak pelvic floor muscles before delivery, but we have no data on pelvic floor muscle strength in these women prior to delivery to confirm this mechanistic hypothesis. If prospective studies confirm that UI during pregnancy identifies women with weak pelvic floor muscles, this group of women could be targeted for pelvic floor exercises or biofeedback to ameliorate their risk of postpartum fecal or UI.

One limitation of this study is that the data are based on self-report, and it is possible, that women who report that they leaked urine during pregnancy are simply more likely to report symptoms in general. While recall bias may affect rates of antenatal UI in this study, we asked this question of subjects during their immediate postpartum hospitalization and see no reason that women would answer the question differently according to how they delivered. We excluded from this study the few women who reported antenatal FI, so we cannot comment on the relationship of this symptom to subsequent symptoms.

Another limitation of the study is that the FISI, which was used to determine presence of FI symptoms, was validated originally in an older, nonobstetric population, and its validity has not yet been established in younger postpartum women. In addition, the 6-month follow-up does not allow conclusions about the relationship between these observed risk factors and long-term continence status.
In summary, while women who sustain an anal sphincter tear are more likely to have postpartum FI, we found few modifiable risk factors that were associated with either postpartum UI or FI. Antenatal UI may be a marker for poor pelvic floor function, which could potentially improve with directed therapy, such as pelvic floor muscle strengthening. Given the strength and consistency of the association between antenatal $\mathrm{UI}$ and postpartum FI and UI, future prospective research is indicated to determine whether identification and intervention decrease future morbidity.

\section{ACKNOWLEDGMENTS}

The authors thank Dr. Robert Park, the Chair of the Pelvic Floor Disorders Network Steering Committee, for his contributions to the network.

Pelvic Floor Disorders Network Members University of Alabama at Birmingham

Holly E. Richter, Ph.D., M.D., Principal Investigator Kathryn L. Burgio, Ph.D., Co-Principal Investigator

Patricia S. Goode, M.D., Co-Investigator

R. Edward Varner, M.D., Co-Investigator

Velria Willis, R.N., B.S.N., Research Coordinator

Baylor College of Medicine

Paul M. Fine, M.D., Principal Investigator

Rodney A. Appell, M.D., Co-Principal Investigator

Peter K. Thompson, M.D., Co-Investigator

Peter M. Lotze, M.D., Co-Investigator

Naomi Frierson, Research Coordinator

\section{University of Iowa}

Ingrid Nygaard, M.D., Principal Investigator

Debra Brandt, R.N., Research Coordinator

Denise Haury, R.N., Research Coordinator

Karl Kreder, M.D., Co-Investigator

Catherine Bradley, M.D., Co-Investigator

Satish Rao, M.D., Co-Investigator

Johns Hopkins Medical Institutes

Geoffrey Cundiff, M.D., Principal Investigator

Victoria Handa, M.D., Co-Investigator

Robert Gutman, M.D., Co-Investigator

Mary Elizabeth Sauter, N.P., Research Coordinator

Jamie Wright, M.D., Co-Investigator

\section{Loyola University, Chicago}

Linda Brubaker, M.D., Principal Investigator

Mary Pat Fitzgerald, M.D., Co-Principal Investigator

Kimberly Kenton, M.D., Co-Investigator

Dorothea Koch, R.N., Research Coordinator

Charity Ball, R.N., Research Coordinator

University of North Carolina at Chapel Hill

Anthony G. Visco, M.D., Principal Investigator

AnnaMarie Connolly, M.D., Co-Investigator

John Lavelle, M.D., Co-Investigator

Mary J. Loomis, R.N., Research Coordinator

Anita K. Murphy, N.P., Research Coordinator 
Ellen C. Wells, M.D., Co-Investigator

William E. Whitehead, Ph.D., Co-Investigator

\section{University of Pittsburgh/Magee-Womens Hospitals}

Halina Zyczynski, M.D., Principal Investigator

Diane Borello-France, Ph.D., Co-Investigator

Judy A. Gruss, B.S., M.S., Research Coordinator

Wendy Leng, M.D., Co-Investigator

Pamela A. Moalli, M.D., Ph.D., Co-Investigator

Elizabeth Sagan, M.D., Co-Investigator

Arnold Wald, M.D., Co-Investigator

Data Coordinating Center: University of Michigan

Morton B. Brown, Ph.D., Principal Investigator

John T. Wei, M.D., M.S., Co-Principal Investigator

Beverly Marchant, R.N., Project Manager

John O.L. DeLancey, M.D., Co-Investigator

Nancy K. Janz, Ph.D., Co-Investigator

Dean G. Smith, Ph.D., Co-Investigator

Patricia A. Wren, Ph.D., Co-Investigator

James Imus, M.S., Statistician

Yang Wang Casher, M.S., Database Programmer

Subcontracting Sites

University of Louisville, Louisville, KY

University of Tennessee, Memphis, TN

Steering Committee Chairman

Robert Park, M.D.

NIH Project Scientist

Anne M. Weber, M.D., M.S.

\section{STUDY HIGHLIGHTS}

\section{What Is Current Knowledge}

- Postpartum fecal incontinence is associated with anal sphincter tears that are recognized and repaired at the time of delivery.

- Postpartum urinary incontinence is associated with antenatal incontinence, body mass index, and obstetrical factors, including vaginal route of delivery and use of forceps.

\section{What Is New Here}

- In women with anal sphincter tears, postpartum fecal incontinence is associated with white race, severity of anal sphincter tear (4th vs 3rd degree tear), older age at time of delivery, antenatal urinary incontinence, and higher predelivery body mass index.

Reprint requests and correspondence: Kathryn L. Burgio, Ph.D., University of Alabama at Birmingham, Birmingham VA Medical Center, 11G, 700 South 19th Street, Birmingham, AL, 35233.

Received October 25, 2006; accepted April 23, 2007.

\section{REFERENCES}

1. Madoff RD, Williams JG, Caushaj PF. Fecal incontinence. N Engl J Med 1992;326:1002-7.

2. Nygaard IE, Rao SS, Dawson JD. Anal incontinence after anal sphincter disruption: A 30-year retrospective cohort study. Obstet Gynecol 1997;89:896-901.

3. Sultan AH, Kamm MA, Hudson CN, et al. Analsphincter disruption during vaginal delivery. N Engl J Med 1993;329:1905-11.

4. Borello-France D, Burgio KL, Richter HE, et al. for The Pelvic Floor Disorders Network. Fecal and urinary incontinence in primiparous women: The Childbirth and Pelvic Symptoms (CAPS) study. Obstet Gynecol 2006;108:863-72.

5. Fynes M, Donnelly VS, O'Connell R, et al. Cesarean delivery and anal sphincter injury. Obstet Gynecol 1998;92:496500 .

6. Schraffordt Koops SE, Vervest HAM, Oostvogel HJM. Anorectal symptoms after various modes of vaginal delivery. Int Urogynecol J 2003;14:244-9.

7. Rockwood TH, Church JM, Fleshman JW, et al. Patient and surgeon ranking of the severity of symptoms associated with fecal incontinence. The Fecal Incontinence Severity Index. Dis Colon Rectum 1999;42:1525-32.

8. Herzog AR, Diokno AC, Brown MB, et al. Two-year incidence, remission, and change patterns of urinary incontinence in noninstitutionalized older adults. J Gerontol Med Sci 1990;45:M67-74.

9. Norton C, Whitehead WE, Bliss DZ, et al. Conservative and pharmacological management of faecal incontinence in adults. In: Abrams P, Cardozo L, Khoury S, Wein A, eds. Incontinence management, Vol. 2. Paris: International Continence Society, 2005:1521-63.

10. Goldberg J, Hyslop T, Tolosa JE, et al. Racial differences in severe perineal lacerations after vaginal delivery. Am J Obstet Gynecol 2003;188:1063-7.

11. Varma MG, Brown JS, Creasman JM, et al. Fecal incontinence in females older than aged 40 years: Who is at risk? Dis Colon Rectum 2006;49:841-51.

12. Pretlove SJ, Radley S, Toozs-Hobson PM, et al. Prevalence of anal incontinence according to age and gender: A systematic review and meta-regression analysis. Int Urogynecol J Pelvic Floor Dysfunct 2006;17:407-17.

13. Baskett TF, O'Connell CM. Severe obstetric maternal morbidity: A 15-year population-based study. J Obstet Gynaecol 2005;25:7-9.

14. Richter HE, Burgio KL, Clements RH, et al. Urinary and anal incontinence in morbidly obese women considering weight loss surgery. Obstet Gynecol 2005;106:1272-7.

15. Bai SW, Kang JY, Rha KH, et al. Relationship of urodynamic parameters and obesity in women with stress urinary incontinence. J Reprod Med 2002;47:559-63.

16. Groutz A, Rimon E, Peled S, et al. Cesarean section: Does it really prevent the development of postpartum stress urinary incontinence? A prospective study of 363 women one year after their first delivery. Neurourol Urodyn 2004;23:2-6.

17. Goldberg RP, Abramov Y, Botros S, et al. Delivery mode is a major environmental determinant of stress urinary incontinence: Results of the Evanston-Northwestern Twin Sisters Study. Am J Obstet Gynecol 2005;193:2149-53.

18. Burgio KL, Zyczynski H, Locher JL, et al. Urinary incontinence in the 12-month postpartum period: A prospective study. Obstet Gynecol 2003;102:1291-8.

19. Mason L, Glenn S, Walton I, et al. The prevalence of stress incontinence during pregnancy and following delivery. Midwifery $1999 ; 15: 120-8$. 
20. Foldspang A, Hvidman L, Mommsen S, et al. Risk of postpartum urinary incontinence associated with pregnancy and mode of delivery. Acta Obstet Gynecol Scand 2004;83:9237.

21. Hvidman L, Foldspang A, Mommsen S, et al. Postpartum urinary incontinence. Acta Obstet Gynecol Scand 2003;82:556-563.

\section{CONFLICT OF INTEREST}

Guarantor of the article: Morton B. Brown, Ph.D.

Specific author contributions: Morton B. Brown, Ph.D., as principal investigator of the coordinating center was responsible for the conduct of the study and had full access to the data and control of the decision to publish. Kathryn L. Burgio, Ph.D.: conception and design, interpretation of data, drafting manuscript. Diane Borello-France, PT, Ph.D.: conception and design, interpretation of data, drafting manuscript. Holly E. Richter, PhD, M.D.: conception and design, interpretation of data, drafting manuscript. Mary Pat FitzGerald, M.D.: conception and design, interpretation of data, drafting manuscript. William Whitehead, Ph.D.: conception and design, interpretation of data, drafting manuscript. Victoria L. Handa, M.D.: interpretation of data, drafting manuscript. Ingrid Nygaard, M.D.: conception and design, interpretation of data, critical revision of manuscript. Paul Fine, M.D.: conception and design, interpretation of data, drafting manuscript. Halina Zyczynski, M.D.: conception and design, interpretation of data, critical revision of manuscript. Anthony G. Visco, M.D.: conception and design, interpretation of data, critical revision of manuscript. Morton B. Brown, Ph.D.: design of study, analysis and interpretation of data, critical revision of manuscript. Anne M. Weber, M.D., M.S.: conception and design, interpretation of data, critical revision of manuscript.

Financial support: This study was supported by grants from the National Institute of Child Health and Human Development (U01 HD41249, U10 HD41268, U10 HD41248, U10 HD41250, U10 HD41261, U10 HD41263, U10 HD41269, and U10 HD41267).

Potential competing interests: None 